\title{
A RELAÇÃO HOMEM-NATUREZA E A PERSPECTIVA HISTÓRICA E CULTURAL DA RELEVÂNCIA DO FATOR CLIMÁTICO NO CONTEXTO DAS DOENÇAS
}

\section{THE MAN-NATURE RELATIONSHIP AND THE CULTURAL AND HISTORICAL PERSPECTIVE OF THE CLIMATIC FACTOR WITHIN THE CONTEXT OF DISEASES}

\author{
Bernardo Elias Correa Soares ${ }^{1}$, Marli Brito Moreira de Albuquerque Navarro² \\ Fundação Oswaldo Cruz/Escola Nacional de Saúde Pública /Núcleo de Biossegurança \\ bernardo@fiocruz.br, mnavarro@fiocruz.br
}

\begin{abstract}
RESUMO
Esta reflexão apresenta algumas questões relativas à saúde e meio ambiente, uma vez que a ocorrência de doenças ligadas às condições climáticas vem demandando novas formulações nas políticas de saúde. Entre as principais questões apontadas, destaca-se a pressão política e sua relação com o processo decisório relacionado ao fenômeno das mudanças climáticas em termos globais e seu impacto sobre a saúde humana e ambiental. Considerando o impacto humano, destaca-se a questão da Saúde Pública, abrangendo os aspectos socioeconômicos, tais como a capacidade produtiva do país e possíveis impactos de desastres naturais ou fenômenos metereológicos que estabelecem preocupações com a saúde das populações.
\end{abstract}

Palavras-chave: Ambiente, Mudanças Climáticas, Política de Saúde, Epidemiologia.

\section{ABSTRACT}

The present paper addresses a few issues concerned with the relationship between health and the environment, since the occurrence of diseases associated with climate changes has been demanding new formulations in health policies over last years. Among the main issues raised, political pressure as related to global climate change and its impact on human and environmental health is pointed out as an influential factor on government decision making. Considering the impact these changes may regard over world human population, public health measures are meant to cover socioeconomic aspects, such as the country's productive capacity and the potential impact of natural disasters or meteorological phenomena that may set up health concerns on affected populations.

Keywords: Environment, Climate Change, Disease, Policies, Public Health, Epidemics. 


\section{INTRODUÇÃO}

Os temas da geografia médica inserem-se, pois, nos estudos sobre a influência do clima vinculado ao fenômeno do surgimento, ressurgimento e disseminação de doenças, haja vista que são sistêmicas as relações entre clima, ambiente, e, especialmente, as doenças infecciosas. Um importante elemento dessa análise é a interferência humana nas mudanças climáticas, um fator relevante.

Sigaud, em seu estudo no inicio do século XIX, já dedicara uma parte deste a apresentar minuciosamente as características climatológicas de cada província brasileira, acrescentando também observações sobre as "trombas d'água" e as neblinas, além de relacionar o clima com as características geológicas de cada região (BERTOLLI FILHO, 2010; SIGAUD IOC/Fiocruz).

O argumento de Santos (2010), também se vale do fato de surgirem novas disciplinas, como a bioclimatologia que estuda os efeitos da radiação sobre os organismos animais e vegetais, enquanto a climatologia médica investiga as possíveis alterações sobre o organismo são ou doente. Assim, conclui Santos (2010), a Geografia Médica está voltada para as preocupações com a saúde, com a doença e com o espaço geográfico, sendo esta interpelação o grande desafio para os profissionais que lidam com a questão do clima e da saúde.

Médicos, naturalistas e outros especialistas, notadamente os estrangeiros que percorreram o país no século XIX, desenvolveram suas observações e estudos sobre a natureza do Brasil e a sua sociedade, enfatizando a determinação climática como fator essencial para distribuição das doenças, e, além disso, atribuía-se também ao clima a conformação dos comportamentos, dos costumes e do senso moral das sociedades construídas nos trópicos. Realçavam nas análises detalhadas sobre a natureza do Brasil, suas características "exóticas". Incluíam nos seus registros as doenças, centrando as principais questões no clima; explicavam, ainda, a natureza social, física e cultural das moléstias identificadas como causa maior dos males que abatiam a população.

"A real inserção dos valores europeus na leitura do Brasil, efetivada pelos naturalistas, não impediu que estes elaborassem a descrição da natureza tropical como esteticamente bela e grandiosa, ao contrário dos médicos que desenharam imagens soturnas, retratos sombrios de uma natureza pestilenta, úmida e quente, propiciadora de hábitos insanos e promíscuos. Apesar das diferenças existentes nos estilos e preocupações dos seus relatos, médicos e naturalistas fundamentaram suas conclusões sobre o paradigma que privilegiava 
a importância da natureza como explicação para a cultura e para o clima como determinantes da saúde das populações e do caráter dos povos.Um outro enfoque sobre a natureza humana do Brasil, também condicionada pelo clima, reconhecia no brasileiro uma vocação nativa para o prazer, para a liberdade e para a libertinagem, características atribuídas ao comportamento coletivo, o que contribuía para o aumento do risco de propagação de doenças. Essa visão foi em parte baseada na observação dos índios, tidos como indolentes, pouco adestrados para o trabalho regular, adeptos das danças e das bebidas fermentadas, traiçoeiros, desconfiados e rebeldes. Quase animais, preferiam a morte ao cativeiro. A intensa proximidade entre brancos, negros e índios, favorecia a expansão de uma mestiçagem degenerada, refrataria à ordem requerida pelas sociedades civilizadas.” (ALBUQUERQUE et al 1999.)

No relato do médico Alphonse Rendu (de 1848) o clima constituía um argumento relevante para explicar hábitos do cotidiano, possibilitando, em parte, o contágio e a propagação de doenças, esse julgamento fazia parte do imaginário europeu sobre um mundo desconhecido, misterioso e primitivo, no qual os homens agiam segundo o clamor da natureza; por isso expressavam livremente seus desejos e eram mais afeitos aos prazeres furtivos. A própria composição física dos habitantes dos trópicos favorecia uma maior agilidade e sensualidade dos gestos e da expressão corporal, o que facilitava o alcance do prazer exigido somente pelo corpo destituído de sentimento e espiritualidade. (ALBUQUERQUE et al. 1999).

Cabe lembrar que como expressão relevante da ideologia, que afirmava ser as regiões tropicais de natureza física, biológica e social inferior, a percepção de Joseph Arthur de Gobineau, o aristocrata nobiliárquico Conde de Gobineau, que exerceu o cargo de diplomata no Rio de Janeiro, representando o governo de Napoleão III, é notória. Gobineau dedicou-se a desenvolver teorias sobre os valores raciais e sua obra mais conhecida intitulou-se "Essai sur l'inégalité dês races humaines" (1853-1855). Considerava que a miscigenação era um dos principais fatores da degenerescência física, moral e intelectual humana. Ao observar a miscigenação brasileira, afirmou que o futuro do Brasil estava seriamente comprometido, uma vez que a população predominantemente mestiça tendia à degeneração física e moral, e, sugeria como alternativa para a construção do futuro brasileiro, o incentivo à imigração europeia, de pessoas de raças superiores.

Estudioso da obra de Gobineau, José Luis Petruccelli mostra-nos um fragmento do "Essai sur l'inégalité des races humaines": "as duas variedades da nossa espécie, a raça negra e a raça amarela, são o fundo grosseiro, o algodão e a lã, que as famílias 
secundárias da raça branca amolecem, nele misturando a sua seda, enquanto que o grupo ariano, fazendo circular suas redes mais finas a traves de gerações enobrecidas, aplica na superfície, em um deslumbrante chef-d'oeuvre seus arabescos de prata e ouro". 1

Gobineau e outros teóricos representantes da aparato ideológico racista afirmavam a superioridade, sobretudo intelectual, dos brancos. Na mesma obra, temos a construção ideológico-racista, observando que "a imensa superioridade dos brancos, no domínio da inteligência, se associa a uma forte inferioridade não menos marcada na intensidade das sensações. O branco é muito menos dotado que o negro e o amarelo no que diz respeito à sensualidade", e até que "seria inexato pretender que todas as misturas sejam ruins e daninhas" (GOBINEAU, 1940, tomo I: 217, apud PETRUCELLI).

Outra importante percepção da Medicina do século XIX, associando a relação entre doença e clima como também de outros aspectos ambientais está presente na obra de José Francisco Xavier Sigaud (1796-1856). A ênfase na ocorrência de doenças a partir das particularidades do clima quente das regiões tropicais está explicitada no trabalho de Sigaud, destacando-se os títulos: "Sur les progrès de la Géographie au Brésil et sur la necessite de dresser une carte générale de cet Empire" e "Du climat et des maladies du Brésil", publicado em Paris, em 1844. Este último, "escrito sob a influência do neo-hipocratismo, exigiu de Sigaud vasto conhecimento da história natural, cultural e social das províncias do Império do Brasil. Seu pressuposto teórico era de que existia forte correlação entre os fenômenos patológicos, o ambiente natural e o padrão sociocultural vigente. Isso explica a estrutura do livro: quatro partes dedicadas, respectivamente, ao detalhamento da climatologia, da geografia médica, da patologia intertropical e da estatística médica do Brasil”. (Ferreira, 1998).

Santos (2010) indica que a maioria dos estudos médicos publicados entre o final do século XIX e a primeira metade do século passado utilizavam os trabalhos de Pasteur como base e com isso articula a crítica hipocrática de que a influência do meio físico sobre o homem e as doenças estavam sendo esquecidos. A partir do estabelecimento dos postulados microbiológicos, as doenças passaram a ser compreendidas no contexto

\footnotetext{
${ }^{1}$ http://bibliotecavirtual.clacso.org.ar/ar/libros/brasil/cpda/estudos/sete/petruc7.htm
} 
da relação entre agente etiológico, alterações fisiopatológicas e sinais clínicos. O paciente e o seu redor passaram para um plano secundário, inserido no ciclo de causa e efeito entre micro-organismo e a lesão resultante. Refere que

"[...] a falta de importância a outros fatores que não privilegiassem somente os micróbios como o responsável pelas doenças levou a certa estagnação da medicina no que diz respeito à compreensão da dinâmica das doenças e as causas da sua distribuição geográfica. Só mais recentemente com estudos sobre a influência do clima na saúde das pessoas, do solo, das chuvas dos ventos é que o tema veio a ser discutido novamente, colocando o ambiente como um dos fatores que exercem forte influência na saúde da população.”(SANTOS, 2010)

No entanto, se analisarmos contextos históricos relacionados às ocorrências mais frequentes das doenças, embora não se atribua determinismo ao fator climático, o ambiente, considerando-se também o ambiente social e cultural, sempre exerceu impacto direto sobre a saúde humana, pois influencia padrões de distribuição de doenças em diferentes grupos populacionais, dependendo das condições de higiene e de recursos hídricos ou mesmo ambientais (biomas) desses grupos. A análise das doenças segundo o espaço no qual se insere é um conceito mais antigo do que a própria epidemiologia como disciplina científica. Se tomarmos como exemplo o estudo de John Snow sobre a epidemia de cólera em Londres, no ano de 1854, a associação entre casos ocorridos e o suprimento de água em partes específicas da cidade mostrou que a relação espacial contribuiu para o entendimento do fenômeno epidêmico: um dos primeiros casos de aplicação desse modelo de geo-saúde no estudo de uma doença. Em seguida, quase um século depois, o conceito de espaço em epidemiologia foi re-apreciado na década de 1930 por Pavlovsky, parasitologista russo, que desenvolveu a teoria de foco natural das doenças transmissíveis ou teoria da nidalidade, na qual ficou premente que o ambiente podia favorecer a circulação de agentes infecciosos, independente da presença humana.

Com a crescente globalização e a multiplicação das ações humanas no ambiente, a natureza intocada passou a ser elemento raro (as sociedades humanas alteraram a natureza por meio das transformações ambientais) e a limitação das doenças infecciosas a faixas geográficas como os "trópicos" ou as regiões de temperatura elevada diminuiu, surgindo a necessidade de rever o conceito de espaço médico-geográfico, na perspectiva de compreender o processo saúde-doença.

Como referem os ensaios de Milton Santos (SANTOS, 2003), a sociedade contemporânea molda-se com base no espaço social e locais ou "nichos" geográficos de 
doenças infeciosas ou parasitárias são produto de um acúmulo de situações históricas, ambientais e sociais que promovem condições particulares para a manutenção de uma determinada doença numa região específica. Da mesma forma como as mudanças populacionais no mundo intensificaram a necessidade de compreensão do impacto dos determinantes sociais na saúde, também na educação o ensino de Ciências demanda de alunos e docentes uma "cultura prevencionista", que permita criar entre os futuros profissionais de qualquer área atitudes de prevenção de doenças e de promoção da saúde ligadas ao espaço.

Em função disso, Barcellos (2010) aponta o meio ambiente como um fator determinante para a prevenção e promoção da saúde, afirmando com propriedade que a integração entre as duas áreas é uma alternativa estratégica ao modelo tradicional que vê distintamente a saúde e a natureza. Um bom exemplo dessa necessidade de integração são as epidemias expressivas que afetam um coletivo grande e que tem em geral sua origem nas condições adversas geradas pelas mudanças climáticas e sobre as quais os indivíduos respondem com doenças. Em geral, essas doenças se vinculam a fatores socioeconômicos e se manifestam mais nas regiões onde há falta de condições de controle, prevenção ou tratamento, agravadas por pendências político-administrativas.

Vemos então que, sob uma visão de conjunto, as questões climáticas vêm ganhando maior importância em paralelo às análises epidemiológicas: a dengue, por exemplo, tem sua incidência pautada por variáveis climáticas e se tornou um dos principais alvos dos programas de Saúde no Brasil, afetando tanto regiões urbanas quanto rurais. Segundo o Ministério da Saúde (Brasil, 2008), trata-se de um problema de geografia médica, pois a dengue tem sua área de proliferação nos trópicos devido ao clima quente e úmido que favorece o mosquito vetor.

Barcellos et. al.(2009) observam que desde seus primórdios a Terra esteve sujeita a mudanças produzidas por ciclos ambientais e meteorológicos mais longos ou mais curtos. Destaca, ainda, que se pode prever com propriedade as mudanças climáticas dos próximos 50 anos, segundo as quais há cerca de $90 \%$ de chance de emissão de gases de efeito estufa e essas mudanças poderão refletir o impacto dos processos socioeconômicos e culturais, tais como a urbanização, o crescimento demográfico e a industrialização no mundo. 


\section{POLÍTICA DE SAÚDE E AS DOENÇAS ENDÊMICAS}

Segundo recomendação da Organização das Nações Unidas (ONU, 2012), presente no estudo conhecido como "Atlas da Saúde e do Clima", as mudanças climáticas

têm se tornado um importante fator de produção de doenças. Quase todas as doenças são sensíveis à temperatura, umidade ou pluviosidade, e, por isso, a saúde humana sofre com as mudanças climáticas e com os desastres naturais: secas, enchentes, vendavais. Tais intempéries podem gerar, além da destruição que causam, surtos epidêmicos: leptospirose, malária, diarreias, pneumonias, meningites. Segundo dados de relatórios sobre a saúde mundial (ONU, 2012), cerca de 2,4\% de todos os casos de diarreia no mundo e $2 \%$ dos casos de malária se devem à mudança climática. Por exemplo, o calor pode produzir erupções, infecções e queimaduras cutâneas, desidratação, fadiga, síncope e até insuficiência respiratória; além disso, há infecções de transmissão ambiental ou que passam pela água ou pelos alimentos para chegar ao hospedeiro humano, como infecções entéricas do tipo cólera ou da salmonelose, que tem clara relação com o aumento da temperatura.

Portanto, as "informações sobre a variabilidade e mudanças climáticas são instrumentos que auxiliam as tarefas de prevenção das doenças". Tais índices vêm sendo "subutilizados" na saúde pública, pois a falta de atenção a esses dados acaba por negligenciar fatores causais importantes, ocorrendo, por conseguinte, um aumento da incidência de doenças infecciosas (ONU, 2012).

Assim, para planejar e executar ações em Saúde Pública é preciso entender o que acontece, como acontece, e os índices de influência da variabilidade das mudanças climáticas nas diferentes regiões. Mormente no Brasil onde há diferenças climáticas extremas em função do tamanho e da diversidade geográfica das suas regiões.

Desse modo, ações de políticas públicas referidas à Saúde necessitam de condições de apropriação e difusão de informações que possam alimentar o sistema integrado de saúde em nível nacional. Outrossim, a complexidade do atual sistema de saúde constitui um obstáculo a mais na produção de informações epidemiológicas completas e confiáveis.

Deve ser considerado, sobretudo, o fato de que a população usuária do sistema público de saúde, em sua maioria, é composta de cidadãos reconhecidamente carentes, o 
que leva a uma tendenciosa variação dos dados em comparação às regiões habitadas por diferentes classes sociais. Embora a estrutura do setor saúde funcione com ampliada perspectiva e competência na conjugação de dados, o próprio Ministério da Saúde (Brasil, 2008), não possui base de dados ou um sistema de registro que possa oferecer informações atuais alcançáveis de forma imediata pelos pesquisadores.

Entretanto, como o país tem uma histórica distribuição desigual de recursos econômicos e materiais, a doença e as epidemias sempre fizeram parte do quadro da saúde com problemas graves e precariamente resolvidos. Nesse ponto, faz-se essencial a intervenção do Poder Judiciário na condição de "tutor" dos cidadãos que necessitam de serviços de saúde, pois a maioria dos serviços só cumpre sua função por força de obrigação. Uma vez que grande montante de recursos são necessários para garantir políticas públicas no contexto coletivo; os principais marcos regulatórios ambientais surgiram em meio a conflitos e vêm respaldando uma contínua demanda judicial aos governos por reparações.

Informações do Ministério da Saúde (Brasil, 2008) lembram que os recursos para a saúde são pequenos em face da grandiosidade da necessidade de assistência e o ponto que não avançou como desejado foi a política de acesso. Dados espaciais com função social, os geodados, precisam ser liberados, estabelecendo uma possibilidade de acesso integrado entre os sistemas de informação de saúde e os sistemas de informações climático-ambientais. Mais que isso, é preciso uma nova compreensão, mais abrangente, para os sistemas de informação em saúde. Face aos novos desafios da vigilância em saúde de base territorial, o acesso aos dados de natureza climática e ambiental de modo mais direto é essencial.

Desse modo, os dados sobre mudanças climáticas e ambientais são responsáveis por um campo de pesquisa que pode conduzir a esclarecimentos importantes sobre as doenças tropicais, endêmicas ou epidêmicas, além de fazer face a melhores condições de assistência Mas para desenvolver esses dados é necessário um investimento grande do governo na formação de pesquisadores capacitados para interpretarem os dados do clima, da saúde, das regiões de maneira integrada, produzindo um conhecimento consciente sobre as vulnerabilidades regionais e sociais. 


\section{O PROTOCOLO DE KIOTO E AS MUDANÇAS CLIMÁTICAS GLOBAIS}

O Protocolo de Kioto (Brasil /MRE), acordo internacional que visa reduzir a emissão de gases na atmosfera por parte dos países signatários, especialmente dos países industrializados, propõe também as iniciativas de desenvolvimento com menor impacto sobre o planeta e sobre a vida das populações.

O Protocolo tem 28 artigos voltados para pactuar a implementação dos compromissos comuns dos países signatários considerando especialmente:

1- formular apropriadamente os programas nacionais; e, conforme o caso, regionais adequados, eficazes em relação aos custos; melhorar a qualidade dos fatores de emissão, dados de atividade e modelos locais que reflitam as condições socioeconômicas de cada Parte para a preparação e atualização periódica de inventários nacionais de emissões antrópicas por fontes e remoções, empregando metodologias a serem acordadas pela Conferência das Partes.

2- implementar, publicar e atualizar regularmente programas nacionais, e, conforme o caso, regionais, que contenham medidas para mitigar e facilitar uma adaptação à mudança do clima.

Observa que tais programas devem envolver, entre outros, os setores de energia, transporte, indústria, bem como os de agricultura, florestas, tratamento de resíduos. Além disso, tecnologias e métodos de adaptação para aperfeiçoarem o planejamento espacial melhorariam a adaptação à mudança do clima.

Além dessas determinações, há previsão de integração cooperativa com outros países, visando o desenvolvimento de práticas e processos ambientalmente seguros relativos à mudança do clima, em particular para os países em desenvolvimento. Inclui a formulação de políticas e programas para a transferência efetiva de tecnologias que sejam de propriedade pública ou de domínio público, além da criação, no setor privado, de acordos políticos para promover e melhorar a transferência de tecnologias e o acesso a elas.

Considerando as iniciativas globais mais recentes, o Brasil e outros países em desenvolvimento não determinaram metas para o quadriênio 2008-2012 em relação ao Protocolo de Kioto (Brasil /MRE). No entanto, o Brasil pôde usufruir dos benefícios do documento, uma vez que propôs projetos e maneiras de redução certificada de emissões.

Uma análise política da conferência revelou que os Estados Unidos minaram os esforços para os debates pós-Protocolo; embora o Protocolo de Kioto tenha incentivado 
as discussões sobre o aquecimento global, mostrando que se pode implementar acordos globais. Esse dado, assim, é o grande mérito do Protocolo, ou seja, de abrir a possibilidade de uma integração menos violenta para o planeta reunindo países do mundo todo, agregando adesões de instituições públicas e privadas de grande importância.

Um outro componente relevante nas políticas vinculadas ao fenômeno global das mudanças climáticas está situado na produção de alimentos. Tal processo associa-se qualidade ambiental e social de grandes populações, trazendo para o contexto a questão da preservação do solo, da biodiversidade, da água, além de estender a preocupação para o monitoramento da relação ambiente e potencialidade do surgimento e ressurgimento de doenças, estando pois neste foco a saúde pública e o valor dos recursos da biossegurança.

As questões que estão no âmbito da saúde pública abrangem igualmente as sequelas da desigualdade econômica. Salienta-se que o Brasil é um país de marcantes diferenças socioculturais regionalizadas, e, essa diversidade se traduz na distribuição de doenças caracterizadas pela dinâmica ambiental, e, sendo esta dinâmica sistêmica, exige a análise dos fatores ambientais, socioeconômicos, políticos e culturais.

Nesse sentido, na perspectiva da diversidade, deve-se considerar os aspectos geográficos, sociais, ecológicos, políticos, culturais, econômicos como presenças no entendimento das consequências das mudanças climáticas e sua associação com as doenças e com a capacidade de intervenção das políticas de saúde pública.

\section{REFERÊNCIAS BIBLIOGRÁFICAS}

AlBuQuerque, M. B. M. de; LiMA E SILVA, F. H. A.; CARDOSO, T. A. O. Doenças tropicais: da ciência dos valores à valorização da ciência na determinação climática de patologias. Ciência. Saúde Coletiva. Rio de Janeiro v. 4, n. 2, jan. 1999 Disponível em http://www.scielosp.org/scielo.php? p. 425

BARCELLOS, C. Integração entre Saúde Meio Ambiente. Inova IcicT n.4, 2010

BARCElloS, C; Monteiro, A. M.; Corvalán, C.; Gurgel, H. C.; Carvalho, M. S. ;Artaxo, P. ; Hacon, S.; Ragoni, V. Mudanças climáticas e ambientais e as doenças infecciosas: cenários e Incertezas para o Brasil. Epidemiologia. Serv. Saúde, Brasília, 18(3):285-304, jul-set 2009.

BERTOLLIFILHO, C. Resenha do livro: SIGAUD, J.F.X . Do clima e das doenças no Brasil ou estatística médica deste império. Rio de Janeiro: Fiocruz; 2009. 434 p. 
(Coleção História e Saúde; Clássicos e Fontes). Cadernos de Saúde Pública, Rio de Janeiro, 26(5):1052-1054, maio de 2010.

BRASIL. Ministério da Saúde. Mudanças climáticas e ambientais e seus efeitos na saúde: cenários e incertezas para o Brasil. BRASIL/Ministério da Saúde; Organização Pan-Americana da Saúde. - Brasília: Organização Pan-Americana da Saúde, 2008.

BRASIL Ministério das Relações Exteriores /MRE. Protocolo de Kioto. Editado pelo Ministério da Ciência e Tecnologia \& Ministério das Relações Exteriores da República Federativa do Brasil.

COSTA, M. A. R. A Ocorrência do Aedes aegypti na Região Noroeste do Paraná: um estudo sobre a epidemia da dengue em Paranavaí - 1999, na perspectiva da Geografia Médica. Dissertação (Mestrado em Institucional em Geografia). Universidade Estadual Paulista - Faculdade Estadual de Educação Ciências e Letras de Paranavaí, Presidente Prudente, 2001. 214 p.

FERREIRA, L. O. José Francisco Xavier Sigaud: um personagem esquecido, uma obra reveladora. História. Ciência. Saúde-Manguinhos, Rio de Janeiro , v. 5, n. 1, June 1998. Availablefrom<http://www.scielo.br/scielo.php?

INSTITUTO OSWALDO CRUZ (IOC /FioCruz). Dicionário Histórico-Biográfico das Ciências da Saúde no Brasil (1832-1930). Casa de Oswaldo Cruz/ verbete: Sigaud, José Francisco Xavier. Disponível em <www.dichistoriasaude.coc.fiocruz.br>. Acesso 22 mar 2013.

ONU. Organização das Nações Unidas. Convenção das Nações Unidas sobre mudança do clima. Pub. ONU, 2012.

Disp. <http://www.onu.org.br/rio20/img/2012/01/convencao_clima.pdf>. Acesso em 22 mar 2013.

PETRUCCELLI, J. L. Doutrinas francesas e o pensamento racial brasileiro, 18701930.

http://bibliotecavirtual.clacso.org.ar/ar/libros/brasil/cpda/estudos/sete/petruc7.htm.

Acesso em 22 mar 2013

RENDU, A. Étudessur Le Brésil. Paris: Chez J-B Baillière, 1848.

SANTOS, F. de O. Geografia médica ou Geografia da saúde? Uma reflexão. Caderno Prudentino de Geografia, n. 32, vol. 1, p. 41-51, jan/jun, 2010

SANTOS, M. Saúde e ambiente no processo de desenvolvimento. Ciência e Saúde Coletiva, RJ n.1, v. 8, p. 309-314, 2003 